\title{
Evaluation of the structural behaviour of a port chamber following damages produced in the refractory lining
}

\author{
Nicolae CONSTANTIN'1, Ştefan SOROHAN' ${ }^{1}$, Mircea SOARE ${ }^{2}$, \\ Viorel ANGHEL ${ }^{1}$ and Mircea GÄVAN' 1 \\ ${ }^{1}$ Laboratory for Structural Integrity Evaluation of Composite Structures, \\ The University "Politehnica" of Bucharest, Romania \\ 2S.C. Nuclear NDT Research \& Services S.R.L., Bucharest, Romania
}

\begin{abstract}
The port chamber used in oil refineries is an exhaust chamber mounted after the catalytic reactor for retaining and unifying the exhaust hot process gases. The thick steel shell has a refractory lining made of refractory cement called gunite or shotcrete. Damages produced in the refractory lining have serious effects on the thermal generated stresses in the steel shell. The research work aimed to find the level of these stresses in a numerical/experimental approach and to evaluate its consequences on the service life of this important component of the oil refinery. A complex sequentially coupled physics thermal-structural analysis was performed using the ANSYS code in order to get the stresses generated by a deep crack in the shotcrete layer. The results concerning the thermal mapping were based on previous inspections made with infrared thermography (IRT) and made possible an estimation of the remained service life of the port chamber.
\end{abstract}

Keywords: Port chamber, shotcrete layer, multiphysics FEM analysis, life-time estimation.

\section{INTRODUCTION}

Generally, the technical problems claimed by industrial customers in Romania in the last 15 years have not demanded high level research and were not considered worth to be mentioned or published in scientific literature. This time, the complexity of the approach required in solving the specific problem occurred in a refinery is clearly surpassing the many more or less artificial problems proposed by various consortia with academic roots and fully deserves to be brought to light.

The purpose of this research work was to determine stresses and strains that appear as a consequence of mechanical and thermal loads in a port chamber of the catalytic cracker installation in service in an oil refinery, having deep cracks in the refractory lining. The results obtained from the thermal and structural analysis were set be used for estimating the remaining life-time of the port chamber. To this end, a multiphysics FEM analysis was performed in order to get the stresses generated by a deep crack in the refractory layer. In this approach, the complexity of the loads was doubled by the complexity of the two-material wall, with extra-difficulties in estimating the mechanical and thermal properties for the refractory component. The results concerning the thermal mapping were based on previous 
inspections made with infrared thermography (IRT), and the resulted stress distribution made possible an estimation of the remaining life of the port chamber.

\section{DESCRIPTION OF THE INSTALATION AND CURRENT STATE OF OPERATING CONDITIONS}

The port chamber is an exhaust chamber mounted after the catalytic reactor for retaining and unifying the exhaust hot process gases. The gasses are evacuated at around $690^{\circ} \mathrm{C}$ and 0.21 $\mathrm{MPa}$ of pressure. The gases exhausted through the port chamber are boiler gases containing carbon, nitric oxides and steam emissions.

The chamber is made of 3 sections mounted vertical on a skirt type support. Each section is made out of $18 \mathrm{~mm}$ thick sheet iron and has a refractory lining of refractory cement which is referred to as gunite or shotcrete. The shotcrete layer has an approximated thickness of $120 \mathrm{~mm}$ and was mounted during the construction of the vessel by spraying it on the walls. On the inside there are welded small iron bars to keep the shotcrete in place. The exterior boiler section rings are made from A516 structural steel by rolling and then welded as specified in the container book - the construction part.

The design temperature for the metal case is $343^{\circ} \mathrm{C}$, as specified in the container book. During normal operation cycles, four areas with very high temperatures appeared on the outside of the chamber. The temperatures measured with thermocouples reached $482^{\circ} \mathrm{C}$ while measurements made by an IRT equipment showed a maximum temperature of $468^{\circ} \mathrm{C}$. These hot spots appeared in the tronconic upper section (Fig. 1, b) and may be observed in the thermography reports (see Fig. 2). The assumptions for this temperature rise were the following: (i) deep cracks have developed in the shotcrete layer and pieces of it have fallen; (ii) the interface between the shotcrete and the metal case has weakened or it is even missing in the areas around the cracks.

This allowed hot gases to reach the outside casing and increase the temperature of the material to the measured values. Also, in this cracks the speed and turbulence of the fluid is increased, driving to a higher convection coefficient.

In order to draw near the design temperature, the company operating the oil refinery mounted perforated steam pipes around first section in order to spray steam at $200^{\circ} \mathrm{C}$. In such conditions, the temperature decreased to $447^{\circ} \mathrm{C}$ in the hottest area (Fig. 2, b).

The multiphysics approach described below attempted to duplicate the complex loading conditions to a FE model able to give a good estimate of the stress/strain state resulting from that.

\section{MODELLING BY FEM}

The target of the finite element analysis was to get the maximum stresses generated in the steel shell around the hottest areas of the port chamber, according to the measured temperature distribution. Considering the measured temperatures as direct loading into a structural analysis is a very complex task, due to the difficulty of mapping of measured temperatures to the actual mesh of the model. Moreover, the measured temperatures are limited only to the outside of the port chamber, consequently some extrapolation techniques must be used. An alternative solution is to obtain the complete temperature distribution using an adequate finite element model in thermal analysis. In this case a sequentially multiphysics coupled analysis may be involved. It was actually the solution followed in the analysis, in the way described below. 

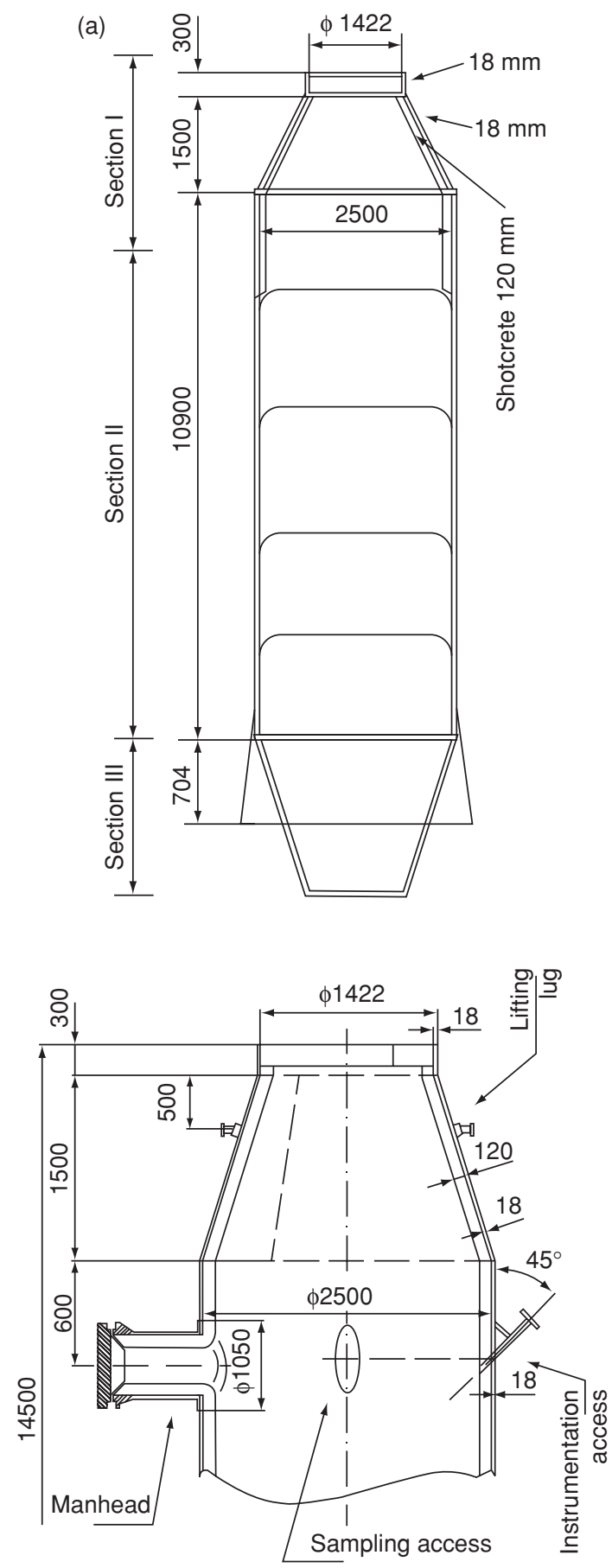

Figure 1 Detailed drawing of the general assembly of the port chamber (a) and $1^{\text {st }}$ section (b). 

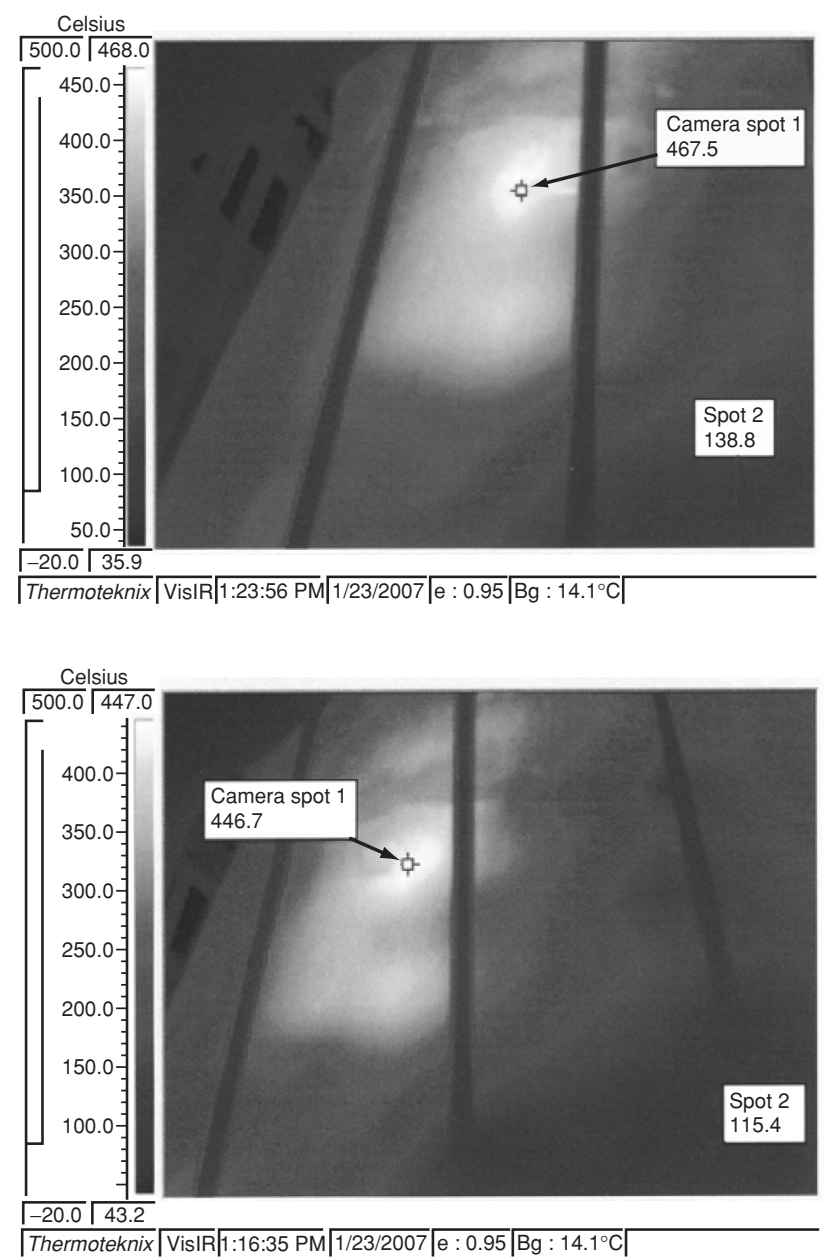

Figure 2 The hottest measured spot. (a) - without steam blown over the hull; (b) - with steam blown over the hull.

A sequentially coupled physics analysis is the combination of analyses from different engineering disciplines which interact to solve a global engineering problem [1]. The term sequentially coupled physics refers to solving one physics simulation after another (Fig. 3). Results from one analysis become inputs for the next analysis. If the analyses are fully coupled, results of the second analysis will change some input to the first analysis.

Due to some unknowns concerning the geometry and location of the cracks in the shotcrete and especially the real boundary conditions in the thermal analysis, the steady state thermal analysis has a supplementary loop of design optimization to fit the imposed thermal boundary condition for obtaining the measured temperatures in some points.

The steady-state thermal analysis was simplified, only conduction and equivalent surface convection are included in the thermal balance. Radiation and mass transfer were neglected in theoretical formulation but they are considered through adequate surface convection coefficients. The global equation of the thermal model, in matrix form, is [2] 


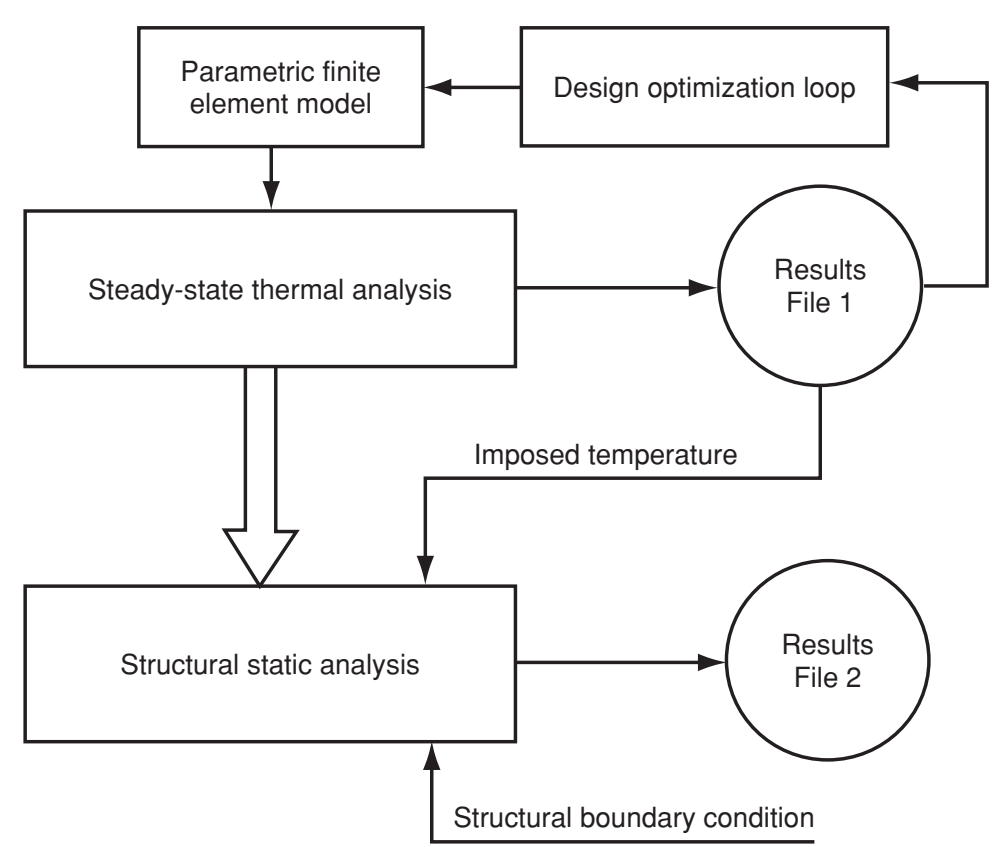

Figure 3 Workflow of the sequentially coupled physics analysis.

$$
\left[K_{t}\right]\{T\}=\{Q\},
$$

where $\left[K_{t}\right]$ is the thermal characteristic matrix, $\{T\}$ is the vector of unknown nodal temperatures and $\{Q\}$ is the thermal load vector. The $\left[K_{t}\right]$ matrix has components from conductivity matrix (conductivity $\lambda$ of the isotropic material) and from surface convection, while $\{Q\}$ is obtained only from surface convection coefficients and bulk temperatures.

The normal heat flow $q$ is obtained from the relation

$$
q=h\left(T_{s}-T_{B}\right)
$$

where $h$ is the film coefficient, $T_{B}$ is the bulk temperature of the adjacent fluid and $T_{S}$ is the temperature at the surface of the model.

A steady-state thermal analysis may be either linear, with constant material properties, or nonlinear, with material properties that depend on temperature. The thermal properties of most materials do vary with temperature, so the analysis is usually nonlinear.

The static structural analysis is described by an equation similar to (1), i. e.

$$
[K]\{U\}=\{F\},
$$

where $[K]$ is the global stiffness matrix, $\{U\}$ is the vector of unknown nodal displacements, and $\{F\}$ is the global load vector obtained from internal pressure and thermal loading. Even for small displacements, the stiffness matrix is nonlinear because it is a function of mechanical material constants like Young's modulus $E$, Poisson ratio $v$, yielding limit $\sigma_{c}$ etc., all functions of temperature.

The thermal expansion coefficient $\alpha$ of a material is function of temperature, and the thermal strain on a linear direction is obtained by 
Table 1 Thermal conductivity of the steel function of temperature

\begin{tabular}{lccccc} 
Temperature $\left[{ }^{\circ} \mathbf{C}\right]$ & $\mathbf{1 0 0}$ & $\mathbf{2 0 0}$ & $\mathbf{3 0 0}$ & $\mathbf{4 0 0}$ & $\mathbf{5 0 0}$ \\
\hline$\lambda[\mathrm{W} / \mathrm{m} / \mathrm{K}]$ & 44 & 41 & 38 & 34 & 30 \\
\hline
\end{tabular}

$$
\varepsilon_{t h}=\alpha_{s}\left(T-T_{r e f}\right),
$$

where $\alpha_{s}$ is the secant coefficient of thermal expansion, $T$ is the current temperature and $T_{\text {ref }}$ is the reference (strain-free) temperature.

In the design optimization module of thermal analysis, we supposed that the temperature of fluids inside and outside the port chamber is known, also the convection film coefficients inside and outside the walls are known, except to the inside $n$ crack zones (denoted $h_{i}, i=$ $1 . . n$ ), where they are to be determined and are considered design variables. The objective function to be minimized in the design loop was defined as

$$
\text { Obj_function }=\sum_{j=1}^{N p}\left(T_{j}^{\text {Anal }}-T_{j}^{E x p}\right)^{2}
$$

where $N_{p}$ is the total number of thermally monitorized points (nodes); $T_{j}^{\text {Anal }}$ is the analytically described temperature in point $j$ and $T_{j}^{E x p}$ is the experimental measured temperature in the same point $j$.

As mentioned before, the upper tronconic part of the port chamber is the most exposed. For that reason, this part was chosen for detailed analysis by FEM. In order to simplify the model, the elements that do not have any significant influence on the stress/strain state in running conditions, like the lifting lugs, were eliminated. The ANSYS code [3] was used for all FEM analysis.

Firstly, a section through the bi-material wall with a discontinuity in the refractory lining produced by a crack was considered and a 2D model was developed. The boundary conditions were successively applied by convection on the free surfaces in order to obtain temperatures as close as possible to the measured ones in the critically exposed areas. Using the thermal 2D model, a coarse control upon the values of the convection coefficients was obtained. The thermal conductivities were taken from literature and those for steel are presented in Table 1, whereas for the shotcrete a constant value $\lambda=1.55 \mathrm{~W} / \mathrm{m} / \mathrm{K}$ was considered.

To simulate the cracks, circular and square holes were created in the volume representing the shotcrete layer, placed one on each of the four quadrants. The dimensions of the cracks were assumed from the data observation, which stated that the high temperature spots had a diameter between $100 \mathrm{~mm}$ and $200 \mathrm{~mm}$ and a height level from the base of the tronconic section of $800 \mathrm{~mm}$ and $1200 \mathrm{~mm}$. So, holes were created at both height levels: with a diameter of $150 \mathrm{~mm}$ for the circular ones and $150 \mathrm{~mm}$ long side for the square ones (Fig. 4, a). The different shapes were also chosen to study the impact of the model over the results. The outside of the port chamber is modelled as a continuous steel volume (Fig. 4, b). A fine brick meshing for section I of the port chamber (Fig. 4, c) was prepared with SOLID70, an 8-node thermal solid finite element. The inside volume, representing the shotcrete, was coarser meshed, because its solely role is to transfer heat from the hot gases to the exterior steel hull. No results were required from the shotcrete volume.

The thermal analysis was performed in order to fit the temperature distribution in the finite element model with that experimentally obtained using infrared thermography, mainly in the hot spot areas. 
(a)

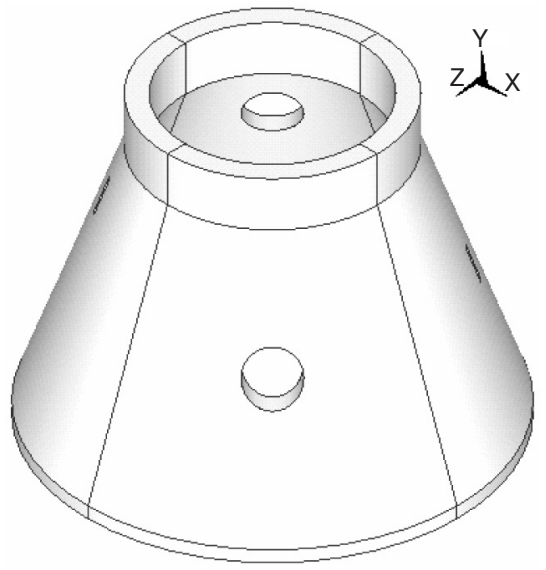

(b)

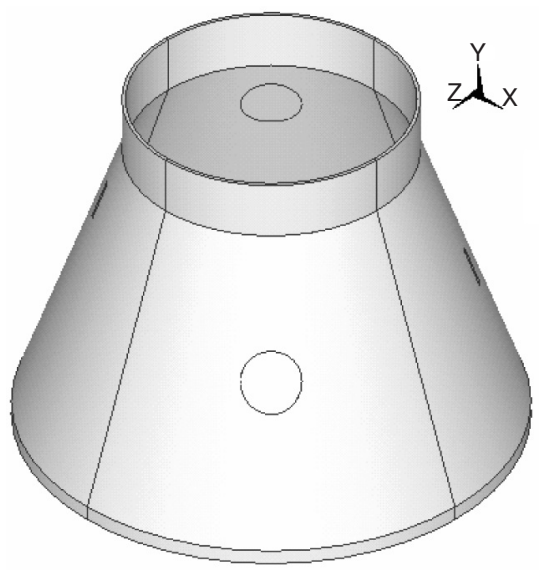

(c)

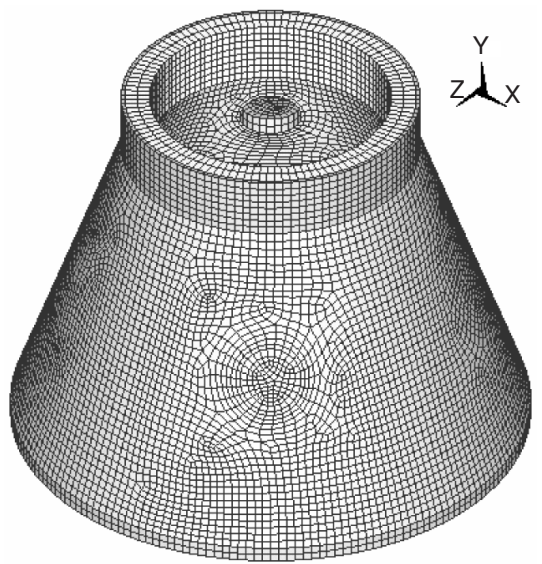

Figure 4 The model of the upper part of the port chamber. a) the shotcrete volume including four holes to model deep cracks; b) the steel volume; c) finite element mesh of the section I. 
Table 2 Thermal loads on the 3D model-convection coefficients and bulk temperatures

\begin{tabular}{|c|c|c|c|c|}
\hline Location & \multicolumn{2}{|c|}{ over the hull } & \multicolumn{2}{|c|}{ over the hull } \\
\hline & $h\left[\mathbf{W} / \mathbf{m}^{2} / \mathbf{K}\right]$ & $T_{B}\left[{ }^{\circ} \mathrm{C}\right]$ & $h\left[\mathbf{W} / \mathbf{m}^{2} / \mathbf{K}\right]$ & $T_{B}\left[{ }^{\circ} \mathrm{C}\right]$ \\
\hline External surface & 88 & 80 & 120 & 130 \\
\hline Internal surface & 90 & 690 & 90 & 690 \\
\hline Internal holes ${ }^{*}$ & 166.61 & 690 & 162.17 & 690 \\
\hline
\end{tabular}

During normal operation of the port chamber, the temperature of the gases coming out of the catalytic reactor is stationary. In such a situation, the problem was considered a steady-state one, for which a sequentially coupled physics thermal-structural analysis is adequate. Two similar boundary conditions were considered, according to the real operating conditions: 1) without steam blown over the hull; 2) with steam blown over the hull.

The thermal loads were applied on surfaces, with the values mentioned in Table 2, and the model was iterated (in the design optimization module) until the desired result was obtained - minimum value of the objective function (5). Because steam at $200^{\circ} \mathrm{C}$ was sprayed through natural environment, it was assumed that the mean temperature on the outside walls of the container was around $130^{\circ} \mathrm{C}$, with forced convection. On the inside walls it was already known that the forced convection produced a mean temperature of the gases of $690^{\circ} \mathrm{C}$. It was also assumed that inside the crack, the convection coefficient increases and it is obtained in the design optimization module. In this analysis, it was introduced $N_{p}=1$ in (5).

The obtained temperature distributions are presented in Figure 5 for the whole model and in Figure 6 only in the steel hull.

For the structural analysis made in the second step, the model was kept without any modifications. The environment was switched from thermal to structural and the implicit 3-D 8-node structural solid element SOLID45 was used. The structural material properties for steel were introduced according to [4] and are presented in Table 3. The stress-strain curve is approximated by bilinear kinematic hardening with yielding limit $\sigma_{y}$ and tangent modulus $E_{p l}$. The shotcrete was considered a linear elastic material, with constant material properties: mass density $\rho=1800 \mathrm{~kg} / \mathrm{m}^{3}$; Young's modulus $E=4 \mathrm{GPa}$; Poisson ratio $v=0.16$; thermal expansion coefficient $\alpha=10 \cdot 10^{-6}\left({ }^{\circ} \mathrm{C}\right)^{-1}$. The structural boundary conditions were appropriately imposed in the lower junction and they do not have an important influence upon the maximum stresses in the crack zones.

The von Mises stresses are presented in Figure 7. In the case of forced convection with steam spraying on the outside, a temperature reduction of about $21{ }^{\circ} \mathrm{C}$ in the hottest area was obtained (Fig. 6), with almost no effect on the equivalent stress distribution (Fig. 7).

\section{APROXIMATION OF THE REMAINING LIFE-TIME}

To approximate the remaining life-time of the container in the given conditions, a stress-time diagram was used for the creep behaviour assessment of the steel hull. According to [4], at $450^{\circ} \mathrm{C}$ the steel has a long technical resistance of $143 \mathrm{MPa} / 10000 \mathrm{~h}$ and $87 \mathrm{Mpa} / 100000 \mathrm{~h}$. By linear extrapolation, the estimated durability for higher working stresses, corresponding to low life-time and actual operating temperatures in the damaged state of the port chamber, 
(a)

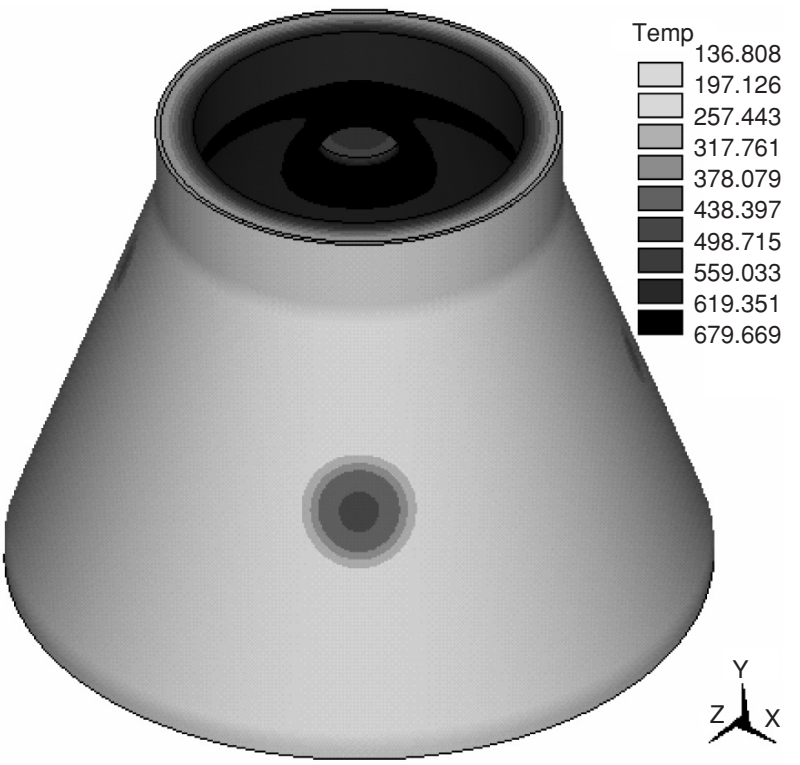

(b)

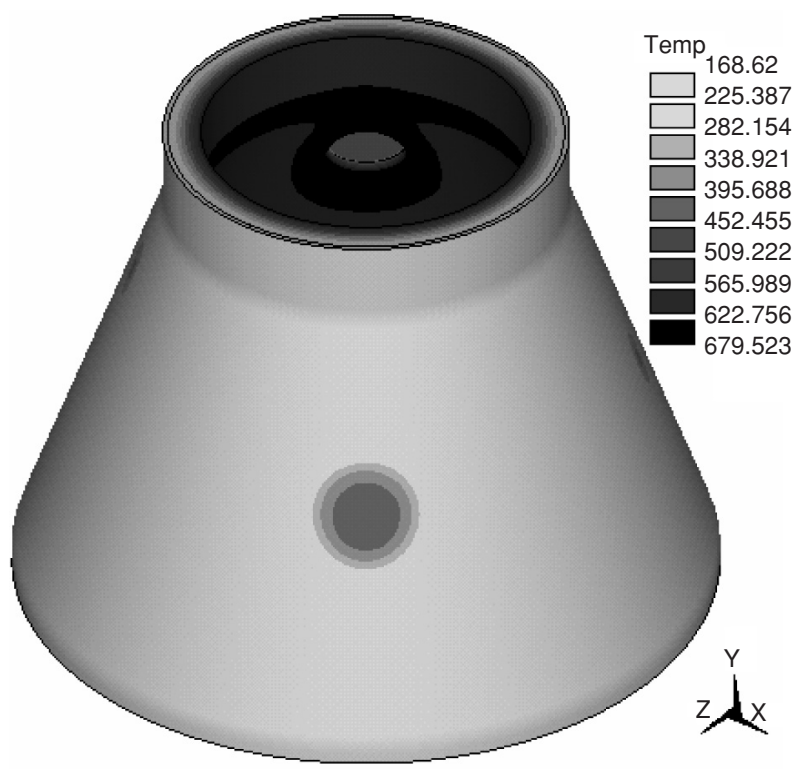

Figure 5 Temperature distribution $\left[{ }^{\circ} \mathrm{C}\right]$ on the whole tronconic section. (a) - without steam blown over the hull; (b) - with steam blown over the hull.

are presented in Fig. 8. With extrapolation for various working temperatures, the conclusion of the evaluation is that the steel case of the port chamber can resist maximum 4000 hours when the material temperature in the hotspot is about $427^{\circ} \mathrm{C}$ (no steam curtain), and can be maximum 6000 hours if the temperature can be kept under $420^{\circ} \mathrm{C}$ (with steam curtain). This is valid only if no unexpected local temperature rising will occur and if the metallic wall thickness is or will not be locally diminished by corrosion. 
(a)

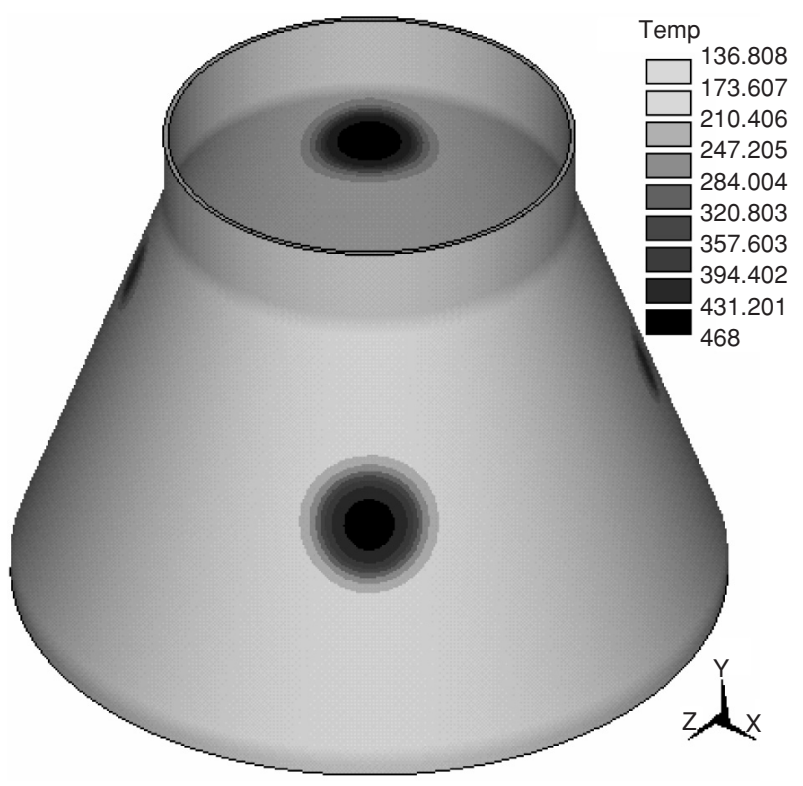

(b)

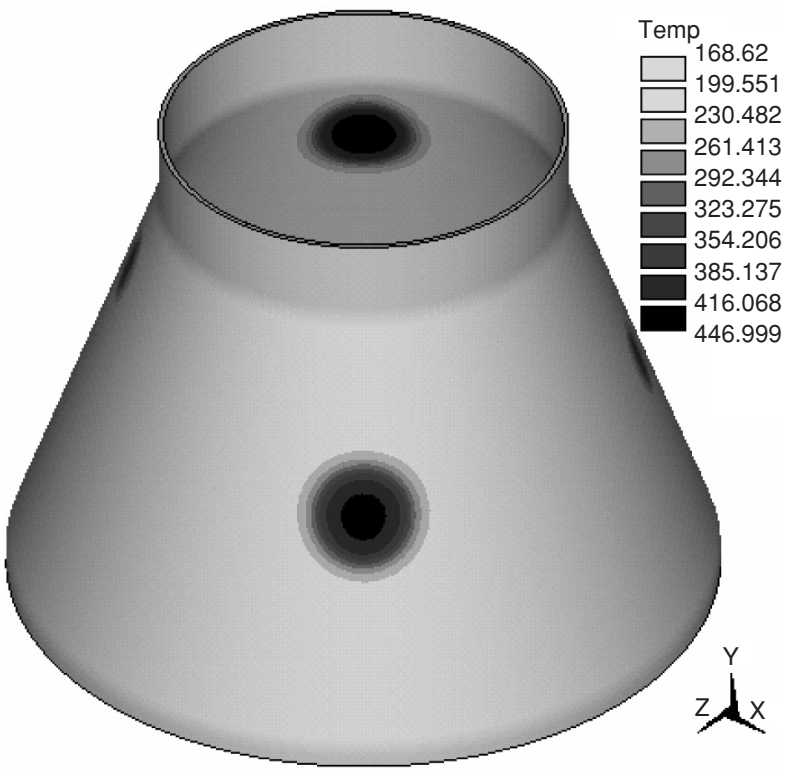

Figure 6 Distribution of temperatures $\left[{ }^{\circ} \mathrm{C}\right]$ only in shell steel in finite element model. (a) - without steam blown over the hull; (b) - with steam blown over the hull.

Fatigue calculations were not possible, as the definition of mechanical and, especially, of thermal cycling was not available.

\section{CONCLUSIONS}

The research work outlined both the necessity and the difficulties of a complex approach in the reliability assessment of sensitive installations, running in difficult conditions. It is essential to retain that these conditions must be known, and that a trusting characterisation 
Table 3 Properties of the steel

Temperature

\begin{tabular}{lcccccccc}
{$\left[{ }^{\circ} \mathbf{C}\right]$} & $\mathbf{2 0}$ & $\mathbf{2 0 0}$ & $\mathbf{2 5 0}$ & $\mathbf{3 0 0}$ & $\mathbf{3 5 0}$ & $\mathbf{4 0 0}$ & $\mathbf{4 5 0}$ & $\mathbf{5 0 0}$ \\
\hline$E[\mathrm{GPa}]$ & 212 & - & - & 192 & - & 183 & - & 175 \\
\hline$v[-]$ & 0.33 & 0.33 & 0.33 & 0.33 & 0.33 & 0.33 & 0.33 & 0.33 \\
\hline$\alpha\left[1 /{ }^{\circ} \mathrm{C}\right]$ & $14 \cdot 10^{-6}$ & $14 \cdot 10^{-6}$ & $14 \cdot 10^{-6}$ & $14 \cdot 10^{-6}$ & $14 \cdot 10^{-6}$ & $14 \cdot 10^{-6}$ & $14 \cdot 10^{-6}$ & $14 \cdot 10^{-6}$ \\
\hline$\sigma_{y}[\mathrm{MPa}]$ & - & 245 & 227 & 205 & 193 & 177 & 168 & - \\
\hline$E_{p l}[\mathrm{GPa}]$ & - & 26.5 & 25.2 & 24.0 & 23.0 & 22 & 21 & - \\
\hline
\end{tabular}

(a)

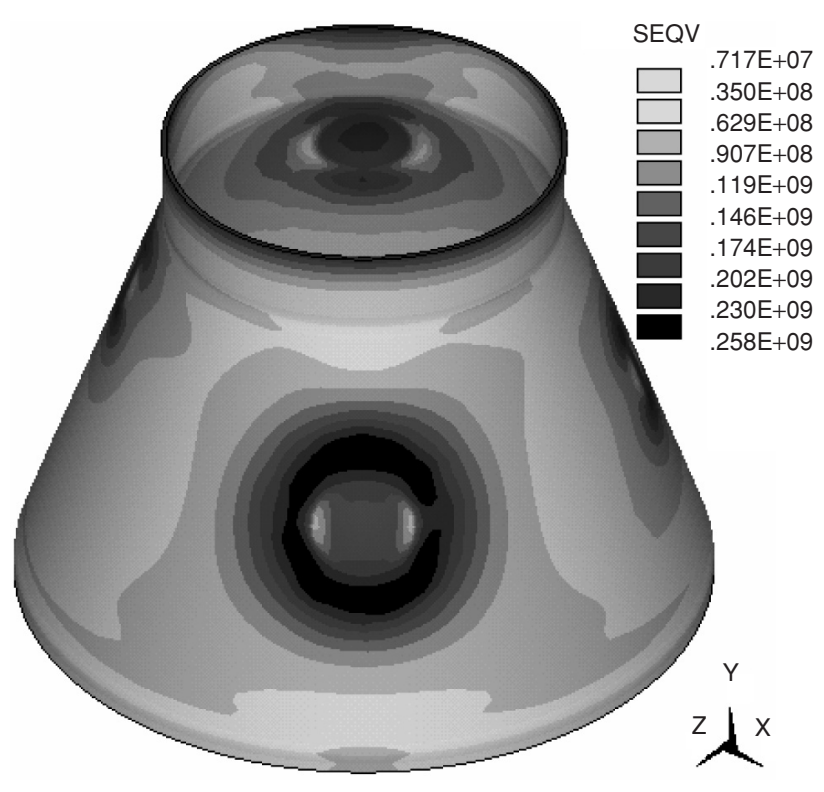

(b)

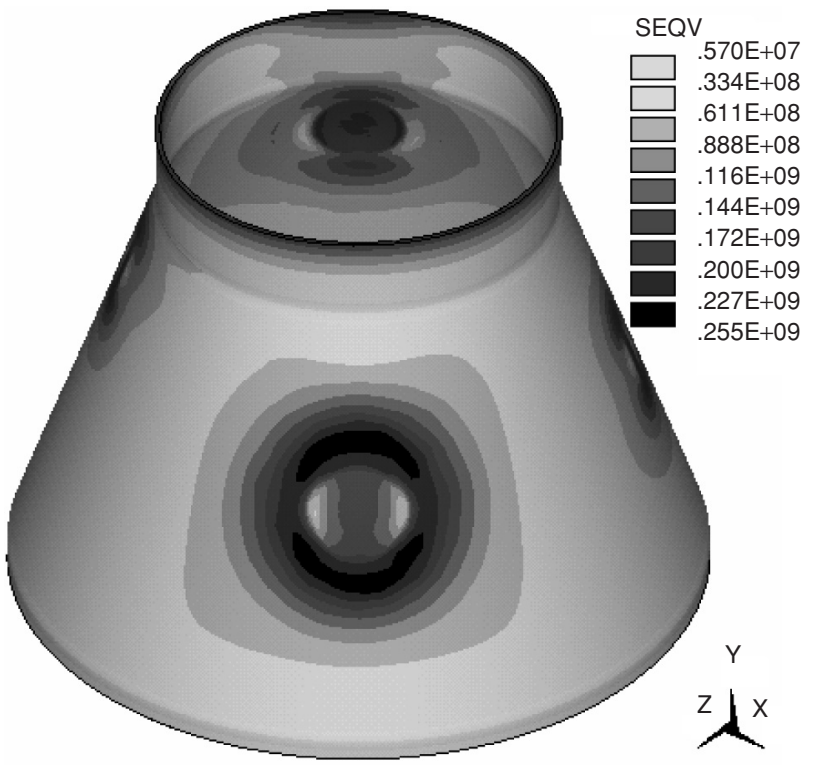

Figure 7 Distribution of the von Mises stresses [Pa] in steel. (a) without steam spraying (b) with steam spraying. 


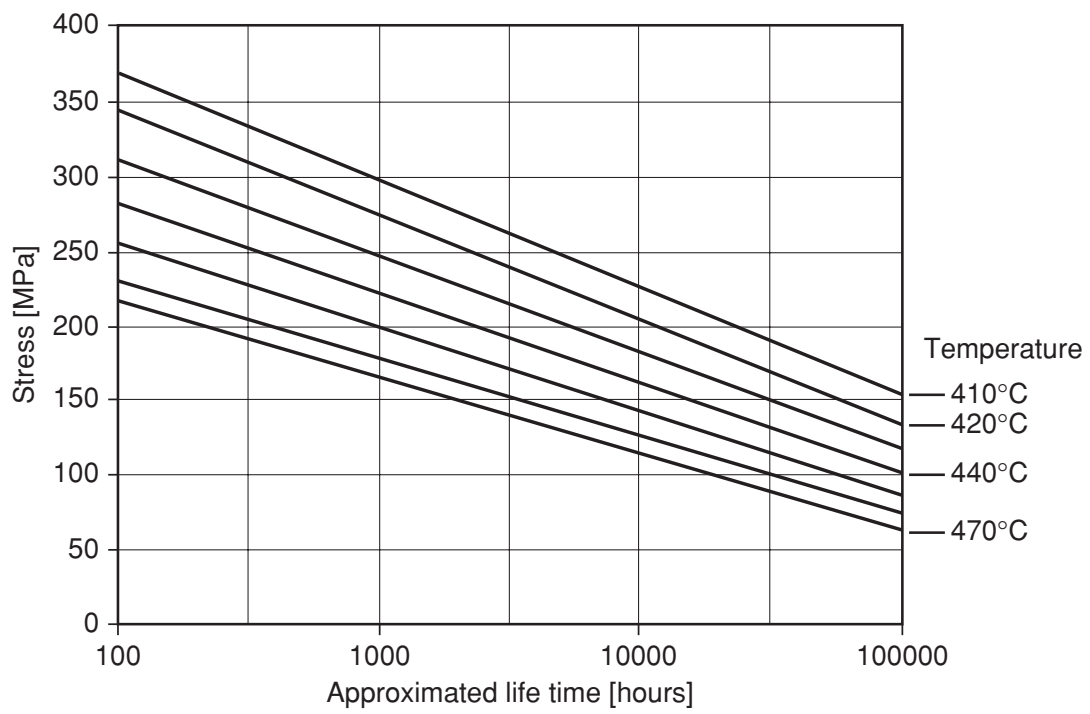

Figure 8 Estimation of the durability of the steel case of the port chamber under various conditions.

of the material is very important, as little changes of the working conditions may have important effect on durability. Improvement of pertinent standards, [5] in this case, can be considered at appropriate terms with the consideration latest developments.

On another hand, the effectiveness of the sequentially coupled physics analysis was proven in a quite complex situation, and the support of experimentally obtained values to back incomplete data on the material and boundary conditions demonstrated the usefulness of a combined numerical/experimental approach. The optimization process proved to be a benefitting extra-option in that multiphysics analysis. Such approaches can also be considered in evaluating the level complexity of coupling in the evaluation of multiphysics analyses [6]. Useless to say that evaluation of commercial codes involving such capabilities, as performed in FENet Thematic Network [5] is very beneficial.

\section{ACKNOWLEDGEMENT}

The research work was supported through the CEEX M4 and M1 projects with DALEISC and CAFICMEIS acronyms, running under contracts nr. 252/2006 and 240/2006, granted by Romanian National Authority for Scientific Research (ANCS).

\section{REFERENCES}

[1] * * * ANSYS Coupled-Field Analysis Guide. ANSYS, Inc., Canonsburg, 2004.

[2] Cook R.D., Malkus D.S., Plesha M.E., Concepts and Applications of Finite Element Analysis, 3rd edn., John Wiley \& Sons, University of Wisconsin-Madison, 1989.

[3] *** ANSYS User Manual, ANSYS, Inc., Canonsburg, 2004.

[4] *** Romanian standard STAS 2883/3-80, Plate steels for pressure vessels at ambient and high temperatures (in Romanian).

[5] *** European standard EN 13445-3:2002 E, Unfired pressure vessels - Part 3: Design.

[6] Cross, M. And Slone, E., FENet - Multi-physics analysis (MPA) themes; a review of commercial MPA capability in 2005, Proc. of FENet Meeting, Malta, 2005, 119-130. 